\title{
Effects of Psychiatric Symptoms on Attention in North Korean Refugees
}

\author{
Yu Jin Lee1, Jin Yong Jun², Juhyun Park', Soohyun Kim¹, Ah Reum Gwak', \\ So Hee $\mathrm{Lee}^{3}$, So Young $\mathrm{Yoo}^{3}$, and Seog Ju Kim ${ }^{1,4} \bowtie$ \\ 'Department of Psychiatry, Seoul National University Hospital, Seoul, Republic of Korea \\ 2Department of Psychiatry, Seoul National Hospital, Seoul, Republic of Korea \\ ${ }^{3}$ Department of Psychiatry, National Medical Center, Seoul, Republic of Korea \\ ${ }^{4}$ Department of Psychiatry, Sungkyunkwan University School of Medicine, Samsung Medical Center, Seoul, Republic of Korea
}

Objective We investigated the performance of North Korean refugees on attention tasks, and the relationship between that performance and psychiatric symptoms.

Methods Sustained and divided attention was assessed using the computerized Comprehensive Attention Test in North Korean refugees and in South Koreans. All participants also completed the Beck Depression Inventory, the Beck Anxiety Inventory, the Impact of Event Scale-Revised and the Dissociative Experiences Scale-II (DES-II).

Results The North Korean refugees showed slower reaction times (RTs) on the visual sustained attention task compared to the South Koreans after controlling for age and sex. North Korean refugees had a greater number of omission errors (OEs) on the divided attention task and a higher standard deviation (SD) of RT. Total DES-II scores of the North Korean refugees were associated with the number of OEs and the SD of RT on the sustained attention task, and with the number of OEs on the divided attention task.

Conclusion North Korean refugees showed poorer performance on computerized attention tasks. In addition, attention deficit among North Korean refugees was associated with their dissociative experiences. Our results suggest that refugees may have attention deficits, which may be related to their psychiatric symptoms, particularly dissociation.

Psychiatry Investig 2016;13(5):480-487

Key Words North Korean refugees, Attention, Depression, Anxiety, Dissociation.

\section{INTRODUCTION}

The 2012 report of the United Nations High Commissioner for Refugees determined that there were 15.4 million refugees worldwide. Refugees commonly have traumatic or stressful experiences, including starvation, imprisonment, violence, torture, poor hygiene, and exile, which are physically and mentally harmful. ${ }^{1}$

The physical and mental problems of refugees can persist even after settlement in safe areas and may hinder their life and well-being. ${ }^{2}$ Among these problems, disturbances in cognitive

Received: January 6, 2016 Revised: January 24, 2016

Accepted: January 28, 2016 Available online: July 11, 2016

$\triangle$ Correspondence: Seog Ju Kim, MD, PhD

Department of Psychiatry, Sungkyunkwan University School of Medicine, Samsung Medical Center, 81 Irwon-ro, Gangnam-gu, Seoul 06351, Republic of Korea

Tel: +82-2-3410-3583, Fax: +82-2-3410-0050, E-mail: psychical@hanmail.net

(c) This is an Open Access article distributed under the terms of the Creative Commons Attribution Non-Commercial License (http://creativecommons.org/licenses/by$\mathrm{nc} / 3.0$ ) which permits unrestricted non-commercial use, distribution, and reproduction in any medium, provided the original work is properly cited. function have a critical impact on the likelihood of successfully adapting to a new society, as cognitive function is essential for coping with rapid changes in socioeconomic status and cultural environment. In particular, attention, which is a state of awareness which maintaining focus on a specific subset among the available perceptual information, is important for learning and storing the novel information continuously encountered in a new society.

Furthermore, refugees are more susceptible to cognitive decline or attentional deficits than other populations. ${ }^{3,4}$ Frequent starvation before and during defection may induce nutritional deficiencies, which hamper brain development and provoke cognitive decline. ${ }^{5,6}$ Refugees are also vulnerable to various psychiatric illnesses closely related to attention, due to stressful or traumatic experiences before and after settlement..$^{7-9}$ Lack of proper education may exacerbate cognitive decline. ${ }^{10}$ However, few studies have investigated attention in refugees.

North Korean refugees are escaping starvation or political repression in North Korea. Approximately 28,000 North Kore- 
an refugees had settled in South Korea by June 2015. North Korea has suffered from economic devastation since the 1990s, which caused a collapse of the public educational system and food shortages. Thus, the cognitive decline of North Koreans could be due to malnutrition and/or low education status. Furthermore, North Korean refugees have commonly experienced various traumatic events before settlement in South Korea, in addition to various economic and cultural difficulties after settlement. ${ }^{11-13}$ As a consequence, North Korean refugees are at high risk for psychiatric symptoms, ${ }^{14-17}$ which are closely related to cognitive dysfunction. Therefore, although attention and cognitive function are essential for North Korean refugees to successfully adapt to their new South Korean environment, they may be more vulnerable to attention deficits or other types of cognitive dysfunction.

In the present study, we examined attention in North Korean refugees using a computerized attention task. This is the first study to evaluate attention in North Korean refugees. We hypothesized that performance on attention tasks would be poorer in North Korean refugees than in South Koreans, and that North Korean refugees' attentional deficits would be associated with their psychiatric symptoms.

\section{METHODS}

\section{Subjects}

A total of 45 North Korean refugees living in South Korea (12 males and 33 females; $35.44 \pm 12.14$ years of age) and 26 native South Koreans ( 6 males and 20 females; $38.58 \pm 13.00$ years of age) were recruited by advertisements and participated in the current study. The mean time between the first departure from North Korea and study participation among the North Korean refugees was $8.88 \pm 5.47$ years. The mean time spent in countries other than North or South Korea during defection was 3.39 \pm 3.92 years, and the mean time of settlement in South Korea was $5.22 \pm 2.72$ years. The study protocol was approved by the Institutional Review Board of Seoul National University Hospital. Following a complete description of the study procedure, written informed consent was obtained from all participants.

\section{Demographic and clinical data}

Demographic data, including age, sex, education, height, and weight were gathered. As the nutritional experiences of refugees may influence attention or other cognitive functions, a questionnaire regarding nutrition was administered to the North Korean refugees, who were requested to report on their experience of starvation in North Korea by choosing one of the following responses: 1) never experienced a food shortage; 2) experienced slight shortage of food; 3 ) skipped meals fre- quently; or 4) serious starvation.

Depressive symptoms were assessed using the Korean version of the Beck Depression Inventory (BDI). ${ }^{18}$ The BDI is a 4-point Likert-type self-report scale with 21 items, most of which describe symptoms related to depressive disorders. Higher BDI scores indicate more severe depressive symptomatology.

Anxiety severity was measured using the Korean version of the Beck Anxiety Inventory (BAI). ${ }^{19}$ The BAI is also a 4-point Likert-type self-report scale with 21 items. The BAI items are concerned with common symptoms of anxiety. Higher BAI scores indicate more severe anxiety.

The Impact of Event Scale-Revised (IES-R) was administered to the North Korean refugees to assess post-traumatic stress disorder (PTSD) symptoms. ${ }^{20}$ The IES-R consists of 22 items pertaining to subjective responses to a specific traumatic event, in terms of PTSD symptoms including intrusion (re-experience), avoidance, and hyperarousal. The IES-R was administered only to the North Korean refugees.

The Dissociative Experiences Scale II (DES-II) was used to assess the dissociative symptoms of the study subjects. The DES-II consists of 28 items that pertain to common dissociative experiences. ${ }^{21}$ The study participants were requested to circle a percentage value (0-100\%) indicating the frequency of dissociative experience for each item. The DES-II consists of three subscales: the amnestic dissociation subscale, the depersonalization and derealization subscale, and the absorption and imaginative involvement subscale. The average percentage scores were calculated for the whole instrument and for each subscale.

\section{Computerized attention test}

Sustained attention and divided attention were assessed using the computerized Comprehensive Attention Test (CAT). The CAT is a modified visual and auditory continuous performance test. The test-retest reliability and validity of the CAT are acceptable. The mean correlation coefficient for test-retest scores on the CAT is 0.715 and explains $51.7 \%$ of the cumulative variance. ${ }^{22}$ The CAT has been used to study attention deficit in individuals with psychotic symptoms, sleep disturbances, or suicidal ideation. ${ }^{23-25}$

There are six subsets in the battery of CAT. Among them, we choose the sustained attention tat and the divided attention task. The sustained attention can be defined as the ability to focus on a specific task for continuing time. The divided attention is the multi-tasking ability to focus on two or more different tasks simultaneously. We assumed that the multi-tasking ability without detriment for a prolonged time would be essential for the refugees' adaptation to the complicated and strange environment in new society. In addition, the sustained attention and the divided attention tasks are more suitable for 
participants with old ages, as high score is more difficult in these tasks.

The visual sustained attention task assesses the ability to maintain a consistent behavioral response during continuous and repetitive activities. Visual stimuli of various shapes are presented every $2 \mathrm{sec}$ for $10 \mathrm{~min}$. Participants are instructed to respond to all shape stimuli except an X-shaped stimulus. Therefore, the task measures the capacity of participants to inhibit responses to certain stimuli under conditions of sustained attention.

The divided attention task demands more attention than the sustained attention task. Divided attention involves the ability to respond simultaneously to multiple tasks or multiple task demands. Auditory and visual stimuli are presented simultaneously every $2 \mathrm{sec}$ for $3 \mathrm{~min} 20 \mathrm{sec}$, and participants are instructed to respond only when an auditory or visual stimulus is the same as that presented within a preceding pair of stimuli.

Two major dependent variables were the numbers of omission errors (OEs) and commission errors (CEs) on each of the two attention tasks. OEs measure inattention and are defined as failures to respond to the target. CEs measures impulsivity and are defined as inappropriate responses to the non-target. Additionally, the reaction times (RT), and the corresponding standard deviation of the RT for correct responses on each of the two attention tasks, were calculated.

\section{Statistical analyses}

Group differences in continuous variables were evaluated using the independent t-test. Between-group comparisons of categorical data were assessed using the chi-square test. In addition, analysis of covariance, with age and sex as covariates, was conducted. Pearson's correlation analysis was conducted to investigate the associations between demographic or clinical data and attentional deficit. A multiple logistic regression analysis (dependent variable: CAT performance; independent variables: age, sex, and clinical/demographic data) controlling for age and sex was also performed. A two-tailed alpha of $<0.05$ was considered significant. The SPSS for Windows (ver. 16.0; SPSS Inc., Chicago, IL, USA) software package was used for all computations.

\section{RESULTS}

\section{Demographic and clinical characteristics}

The demographic and clinical characteristics of the study subjects are presented in Table 1. No differences in the age or sex ratio were observed between the North Korean refugees and the South Korean subjects. The South Korean subjects were significantly taller than the North Korean refugees $(t=2.71$, $\mathrm{p}=0.01)$. The South Koreans also had a higher educational sta- tus than the North Korean refugees $(t=3.89, \mathrm{p}<0.01)$. The BDI and BAI scores were significantly higher in the North Korean refugees than in the South Koreans $(\mathrm{t}=3.32, \mathrm{p}<0.01$; and $\mathrm{t}=5.69, \mathrm{p}<0.01$, respectively). Among the DES-II subscales, the depersonalization score was significantly higher in the North Korean refugees than in the South Koreans $(t=2.21, p=0.03)$.

The South Korean subjects were taller than the North Korean refugees, even after controlling for sex and age $(\mathrm{F}=14.08$, $\mathrm{p}<0.001)$. The BDI and BAI scores of the North Korean refugees were significantly higher than those of the South Koreans after controlling for sex and age $(\mathrm{F}=15.67, \mathrm{p}<0.001$; and $\mathrm{F}=29.62$ $\mathrm{p}<0.001$, respectively). The total DES-II score was significantly higher in North Koreans ( $\mathrm{F}=5.07, \mathrm{p}=0.02)$ than in South Koreans after controlling for sex and age. Among the three DES-II subscales, the amnesia and depersonalization subscale scores were higher in the North Koreans than in the South Koreans after controlling for age and $\operatorname{sex}(\mathrm{F}=4.15, \mathrm{p}=0.05$; and $\mathrm{F}=10.85$, $\mathrm{p}<0.01$, respectively). The absorption scores of the North Koreans tended to be higher than those of the South Koreans $(\mathrm{F}=2.86, \mathrm{p}=0.096)$.

Among all study subjects, females had significantly higher BDI scores than males $(t=2.64, \mathrm{p}=0.01)$. Age was correlated negatively with height $(\mathrm{r}=-0.29, \mathrm{p}=0.01)$ and positively correlated with BDI score $(\mathrm{r}=0.47, \mathrm{p}<0.001)$. Female North Korean refugees showed significantly higher BDI scores than males $(\mathrm{t}=2.46, \mathrm{p}=0.02)$. In contrast, the DES-II score was significantly higher in male refugees compared to female refugees $(t=2.20$, $\mathrm{p}=0.03)$. Age was positively correlated with the BDI ( $\mathrm{r}=0.73$, $\mathrm{p}<0.001)$, BAI $(\mathrm{r}=0.59, \mathrm{p}<0.001)$, and IES-R values among the North Korean refugees $(r=0.51, p<0.01)$.

\section{Performance on attention tasks}

The performance results on the attention tasks are provided in Table 2. The North Korean refugees had a slower RT on the visual sustained attention task $(\mathrm{t}=2.23, \mathrm{p}=0.03)$ and on the divided attention task $(t=2.11, \mathrm{p}=0.04)$ compared to the South Koreans. The North Korean refugees also had more OEs $(\mathrm{t}=3.42, \mathrm{p}<0.01)$ and a higher SD of RT $(\mathrm{t}=2.45, \mathrm{p}=0.02)$ on the divided attention task, and tended to have more CEs on the divided attention task, than the South Koreans ( $\mathrm{t}=1.74, \mathrm{p}=0.09$ ).

Among all study subjects, males showed a significantly higher number of CEs $(\mathrm{t}=2.87, \mathrm{p}<0.01)$ and a faster $\mathrm{RT}(\mathrm{t}=3.12$, $\mathrm{p}<0.01)$ compared to females on the visual sustained attention task. Age was negatively correlated with CEs $(\mathrm{r}=-0.28, \mathrm{p}=0.02)$, and positively correlated with RT ( $\mathrm{r}=0.51, \mathrm{p}<0.001)$, on the sustained attention task. Age was also positively correlated with RT on the divided attention task $(\mathrm{r}=0.27, \mathrm{p}=0.02)$. Among the North Korean refugees, males showed a significantly higher number of CEs $(t=2.97, \mathrm{p}<0.01)$ and a faster $\mathrm{RT}(\mathrm{t}=3.30$, $\mathrm{p}<0.01)$ than female refugees on the visual sustained attention 
task. On the divided attention task, RT was faster in male refugees than in female refugees $(t=2.02, \mathrm{p}=0.05)$. Age was negatively correlated with $\mathrm{CE}$ on the sustained attention task ( $\mathrm{r}=$ $-0.32, \mathrm{p}=0.04$ ), and positively correlated with RT on the sustained task $(r=0.57, \mathrm{p}<0.001)$ among the North Korean refugees.

After controlling for age and sex, the North Korean refugees had a slower RT than that of the South Koreans on the visual sustained attention task $(\mathrm{F}=5.90, \mathrm{p}=0.02)$. In addition, the North Koran refugees had a greater number of OEs $(\mathrm{F}=9.96$, $\mathrm{p}<0.01)$ and a higher SD of RT $(\mathrm{F}=6.01, \mathrm{p}=0.02)$ on the divided attention task compared to the South Koreans after controlling for age and sex. Although non-significant, the North Korean refugees also tended to have a greater number of CEs $(\mathrm{F}=3.70, \mathrm{p}=0.06)$ and a slower $\mathrm{RT}(\mathrm{F}=3.69, \mathrm{p}=0.06)$ on the di- vided attention task than the South Koreans after controlling for age and sex.

\section{Association between psychiatric symptoms and performance on attention tasks}

Among all study subjects, years of education was negatively correlated with OEs, RT, and the SD of RT on the divided attention task ( $\mathrm{r}=-0.28, \mathrm{p}=0.02 ; \mathrm{r}=-0.36, \mathrm{p}<0.01$; and $\mathrm{r}=-0.39$, $\mathrm{p}<0.01$, respectively). Height was negatively correlated with RT on the visual sustained task $(\mathrm{r}=-0.37, \mathrm{p}<0.01)$ and on the divided attention task $(\mathrm{r}=-0.27, \mathrm{p}=0.03)$.

The BDI score was positively correlated with RT and SD of the RT on the visual sustained task ( $\mathrm{r}=0.39, \mathrm{p}<0.01$; and $\mathrm{r}=0.34$, $\mathrm{p}<0.01$, respectively) and OEs and CEs on the divided atten-

Table 1. Demographic and clinical characteristics of study subjects

\begin{tabular}{|c|c|c|c|c|}
\hline & North Korean refugees $(\mathrm{N}=45)$ & South Koreans $(\mathrm{N}=26)$ & +2 & P \\
\hline & Mean \pm SD $(\mathrm{N}, \%)$ & Mean \pm SD $(\mathrm{N}, \%)$ & $\cos x$ & p-value \\
\hline Age & $35.44 \pm 12.14$ & $38.58 \pm 13.00$ & $\mathrm{t}=1.02$ & 0.31 \\
\hline \multicolumn{5}{|l|}{ Gender } \\
\hline Male & $12(26.67)$ & $6(23.08)$ & $\chi^{2}=0.1$ & 0.73 \\
\hline Female & $33(72.88)$ & $20(76.92)$ & & \\
\hline \multicolumn{5}{|l|}{ Weight/height } \\
\hline Height $(\mathrm{cm})$ & $158.93 \pm 6.90$ & $163.62 \pm 7.23$ & $\mathrm{t}=2.71$ & 0.01 \\
\hline Weight (kg) & $56.52 \pm 8.96$ & $57.35 \pm 7.59$ & $\mathrm{t}=0.39$ & 0.69 \\
\hline Education (years) & $11.63 \pm 3.96$ & $15.42 \pm 3.94$ & $\mathrm{t}=3.89$ & $<0.01$ \\
\hline \multicolumn{5}{|l|}{ Experience of starvation } \\
\hline Never experienced a food shortage & $17(37.78)$ & - & & \\
\hline Experienced slight shortage of food & $23(51.11)$ & - & & \\
\hline Skipped meal frequently & $2(4.44)$ & - & & \\
\hline Serious starvation & $3(6.67)$ & - & & \\
\hline \multicolumn{5}{|l|}{ Depression \& anxiety } \\
\hline BDI score & $16.69 \pm 14.57$ & $6.44 \pm 6.31$ & $\mathrm{t}=3.32$ & $<0.01$ \\
\hline BAI score & $20.73 \pm 14.45$ & $3.58 \pm 3.41$ & $\mathrm{t}=5.69$ & $<0.01$ \\
\hline \multicolumn{5}{|l|}{ PTSD symptoms } \\
\hline \multicolumn{5}{|l|}{ IES-R score } \\
\hline Intrusion & $10.20 \pm 8.61$ & - & & \\
\hline Avoidance & $8.97 \pm 7.51$ & - & & \\
\hline Hyperarousal & $7.11 \pm 6.32$ & - & & \\
\hline Total score & $24.78 \pm 21.00$ & - & & \\
\hline \multicolumn{5}{|l|}{ Dissociative experiences } \\
\hline \multicolumn{5}{|l|}{ DES-II score } \\
\hline Amnesia & $8.98 \pm 13.74$ & $4.73 \pm 6.94$ & $\mathrm{t}=1.46$ & 0.15 \\
\hline Depersonalization & $9.66 \pm 15.25$ & $2.63 \pm 6.70$ & $\mathrm{t}=2.21$ & 0.03 \\
\hline Absorption & $14.67 \pm 14.96$ & $9.47 \pm 13.81$ & $\mathrm{t}=1.43$ & 0.16 \\
\hline Total mean & $11.34 \pm 13.58$ & $6.20 \pm 9.98$ & $t=1.67$ & 0.10 \\
\hline
\end{tabular}

BDI: Beck Depression Inventory, BAI: Beck Anxiety Inventory, PTSD: post-traumatic stress disorder, IES-R: Impact of Event Scale-Revised, DES-II: Dissociative Experiences Scale-II 
tion task ( $\mathrm{r}=0.35, \mathrm{p}<0.01$; and $\mathrm{r}=0.28, \mathrm{p}=0.02$, respectively). The BAI score was also correlated with RT and the SD of the RT on the visual sustained task $(r=0.36, \mathrm{p}<0.01$; and $\mathrm{r}=0.37$, $\mathrm{p}<0.01$, respectively) and OEs and CEs on the divided attention task ( $\mathrm{r}=0.30, \mathrm{p}=0.02$; and $\mathrm{r}=0.38, \mathrm{p}<0.01$, respectively). The total DES-II score was correlated with the CE and the SD of RT on the visual sustained attention task $(r=0.27, p=0.03$; and $\mathrm{r}=0.35, \mathrm{p}<0.01$, respectively) and with the OEs and CEs on the divided attention task $(r=0.27, p=0.03$; and $r=0.26$, $\mathrm{p}=0.03$, respectively).

The correlations between performance on attention tasks and the clinical characteristics among the North Korean refugees are shown in Table 3. Performance on the attention tasks was not associated with education or experiences of starvation among the North Korean refugees. Although height was asso- ciated with the number of CEs on the visual sustained attention task $(\mathrm{r}=0.30, \mathrm{p}=0.05)$ among the North Korean refugees, this association was no longer significant after controlling for age and sex. The BDI value of the North Korean refugees was positively correlated with RT on the visual sustained attention task ( $\mathrm{r}=0.40, \mathrm{p}=0.01)$, and BAI score was positively correlated with RT $(r=0.35, p=0.04)$ and the SD of the RT ( $r=0.30$, $\mathrm{p}=0.05$ ) on the visual sustained attention task. However, both the BDI and BAI scores of the North Korean refugees no longer correlated with attention task performance after controlling for age and sex. The IES-R score was not associated with attention task performance among the North Korean refugees.

The total DES-II score was positively correlated with the number of OEs $(r=0.40, p<0.01)$ and the SD of the RT $(r=0.40$, $\mathrm{p}<0.01$ ) on the visual sustained attention task, as well as with

Table 2. Performance on attention tasks of study subjects

\begin{tabular}{|c|c|c|c|c|}
\hline & North Korean refugees $(\mathrm{N}=45)$ & South Koreans $(\mathrm{N}=26)$ & & l \\
\hline & Mean \pm SD & Mean \pm SD & $\mathrm{t}$ & p-value \\
\hline$\overline{\text { Sustained att }}$ & & & & \\
\hline $\mathrm{OE}($ no) & $2.13 \pm 3.81$ & $4.96 \pm 15.64$ & 1.16 & 0.25 \\
\hline CE (no) & $9.56 \pm 9.02$ & $7.69 \pm 7.54$ & 0.89 & 0.38 \\
\hline $\mathrm{RT}(\mathrm{ms})$ & $450.61 \pm 77.72$ & $411.38 \pm 58.36$ & 2.23 & 0.03 \\
\hline SD of RT & $109.42 \pm 46.38$ & $90.72 \pm 25.6$ & -1.89 & 0.06 \\
\hline Divided atte & & & & \\
\hline $\mathrm{OE}$ (no) & $11.98 \pm 7.59$ & $5.77 \pm 6.98$ & 3.42 & $<0.01$ \\
\hline CE (no) & $7.80 \pm 10.12$ & $4.27 \pm 2.55$ & 1.74 & 0.09 \\
\hline $\mathrm{RT}(\mathrm{ms})$ & $708.75 \pm 114.69$ & $648.18 \pm 119.64$ & 2.11 & 0.04 \\
\hline SD of RT & $261.41 \pm 72.71$ & $216.35 \pm 78.26$ & 2.45 & 0.02 \\
\hline
\end{tabular}

OE: omission error, CE: commission error, RT: mean reaction time to correct Responses, SD: standard deviation

Table 3. Correlation between the performances in attention tasks and the clinical characteristics in North Korean refugees

\begin{tabular}{|c|c|c|c|c|c|c|c|c|}
\hline & \multicolumn{4}{|c|}{ Sustained attention } & \multicolumn{4}{|c|}{ Divided attention } \\
\hline & $\mathrm{OE}(\mathrm{no}), \mathrm{r}$ & $\mathrm{CE}$ (no), r & $\mathrm{RT}(\mathrm{ms}), \mathrm{r}$ & SD of RT, r & $\mathrm{OE}$ (no), $\mathrm{r}$ & $\mathrm{CE}$ (no), r & $\mathrm{RT}(\mathrm{ms}), \mathrm{r}$ & SD of RT, $r$ \\
\hline Education (years) & 0.06 & -0.08 & 0.04 & 0.10 & -0.14 & 0.16 & -0.21 & -0.28 \\
\hline Height & 0.19 & $0.30^{*}$ & -0.28 & -0.04 & 0.14 & -0.04 & -0.13 & -0.06 \\
\hline Weight & 0.04 & 0.16 & -0.18 & -0.05 & 0.21 & -0.12 & -0.15 & -0.07 \\
\hline Experience of starvation & 0.19 & 0.16 & -0.09 & 0.00 & -0.16 & 0.14 & -0.20 & -0.02 \\
\hline BDI scores & 0.07 & -0.10 & $0.40^{*}$ & 0.30 & 0.27 & 0.23 & 0.07 & 0.07 \\
\hline BAI scores & 0.26 & -0.10 & $0.35^{*}$ & $0.33^{*}$ & 0.12 & 0.32 & -0.09 & 0.04 \\
\hline IES-R scores (total) & -0.21 & -0.19 & 0.20 & -0.01 & 0.26 & 0.12 & 0.00 & -0.07 \\
\hline \multicolumn{9}{|l|}{ DES-II scores } \\
\hline Amnesia & $0.64^{\dagger}$ & 0.22 & 0.11 & $0.51^{\dagger}$ & 0.24 & 0.24 & -0.29 & -0.18 \\
\hline Depersonalization & $0.62^{\dagger}$ & 0.30 & -0.04 & $0.43^{\dagger}$ & 0.27 & 0.24 & $-0.36^{*}$ & -0.12 \\
\hline Absorption & $0.49^{\dagger}$ & 0.29 & 0.00 & $0.35^{*}$ & $0.38^{*}$ & 0.26 & $-0.35^{*}$ & -0.17 \\
\hline Total mean & $0.59^{\dagger}$ & 0.26 & 0.07 & $0.45^{\dagger}$ & $0.31^{*}$ & 0.25 & $-0.32 *$ & -0.17 \\
\hline
\end{tabular}

${ }^{*} \mathrm{p}<0.05,{ }^{\dagger} \mathrm{p}<0.01$. OE: omission error, CE: commission error, RT: mean reaction time to correct Responses, SD: standard deviation, BDI: Beck Depression Inventory, BAI: Beck Anxiety Inventory, IES-R: Impact of Event Scale-Revised, DES-II: Dissociative Experiences Scale-II 
the number of OEs $(r=0.40, p=0.05)$ on the divided attention task, among the North Korean refugees. Even after controlling for age and sex, total DES-II score was correlated with the number of OEs (beta $=0.55, \mathrm{p}<0.01$ ) and the SD of the RT $(\mathrm{r}=0.50, \mathrm{p}<0.01)$ on the visual sustained attention task, and with the number of OEs $(r=0.38, p=0.03)$ on the divided attention task. Although the DES-II scores of the North Korean refugees were negatively correlated with RT $(\mathrm{r}=-0.32, \mathrm{p}=0.04)$ on the visual sustained attention task, this association was no longer significant after controlling for age and sex.

The number of OEs on the visual sustained attention task was positively correlated with the amnesia $(r=0.64, p<0.01)$, depersonalization $(\mathrm{r}=0.62, \mathrm{p}<0.01)$, and absorption $(\mathrm{r}=0.49$, $\mathrm{p}<0.01)$ DES-II subscale scores among the North Korean refugees. These associations remained significant after controlling for age and sex (amnesia subscale: beta $=0.58, \mathrm{p}<0.01$; depersonalization subscale: beta $=0.57, \mathrm{p}<0.01$; and absorption subscale: beta $=0.43, \mathrm{p}<0.01$ ). The SD of the RT on the visual sustained attention task was positively correlated with the amnesia $(\mathrm{r}=0.51, \mathrm{p}<0.01)$, depersonalization $(\mathrm{r}=0.43, \mathrm{p}<0.01)$, and absorption ( $\mathrm{r}=0.35, \mathrm{p}=0.03)$ DES-II subscale scores. These correlations remained significant after controlling for age and sex (amnesia subscale: beta $=0.55, \mathrm{p}<0.01$; depersonalization subscale: beta $=0.53, \mathrm{p}<0.01$; and absorption subscale: beta $=0.37$, $\mathrm{p}=0.03$ ). The number of OEs on the divided attention task was positively correlated with the DES-II amnesia subscale score $(\mathrm{r}=0.36, \mathrm{p}=0.04)$, which remained significant after controlling for age and sex (beta $=0.45, \mathrm{p}<0.01$ ). Although the RT on the visual sustained attention task among North Korean refugees was negatively correlated with the depersonalization $(\mathrm{r}=-0.36$, $\mathrm{p}=0.02)$ and absorption ( $\mathrm{r}=-0.35, \mathrm{p}=0.02)$ DES-II subscale scores, these associations were no longer significant after controlling for age and sex.

\section{DISCUSSION}

In the present study, North Korean refugees had slower RTs during sustained attention, more OEs, and a higher SD of the RT on the divided attention task compared to the South Koreans. The study also showed that the dissociative experiences of North Korean refugees were associated with more OEs and a higher SD of RT on the sustained attention task, and with more OEs on the divided attention task.

In agreement with our hypothesis, performance on the attention tasks was poorer in the North Korean refugees than in native South Koreans. Our results suggest that refugees are more vulnerable to attention deficits. Attention deficits may be induced by various physical, mental, or environmental problems that are frequently encountered by refugees, and which may persist even after settlement.
There are several probable causes for attention deficits among North Korean refugees. As North Korean refugees are generally less well educated than South Koreans, due to the abolishment of the public education system in North Korea, poor performance on cognitive tasks may be due to a low education level. However, the computerized attention task used in the current study was not heavily dependent on acquired knowledge or intelligence. Furthermore, no relationship was observed between the attentional performance of the North Korean refugees and their education level.

Malnutrition during early brain development is another reason for attention deficits among North Korean refugees. As life-threatening starvation was very common in North Korea during the 1990s, starvation may have hindered brain maturation and induced cognitive retardation. However, we found no association between attention task performance and starvation experience. Furthermore, the height of North Korean refugees, which usually reflects nutritional history during early development, did not independently predict attention task performance. Therefore, it is less likely that the attention deficits of the North Korean refugees were due to low education status or malnutrition.

Psychiatric symptoms are another reason for attention deficits among North Korean refugees. Consistent with previous reports, ${ }^{14-17}$ the current results also showed that the North Korean refugees were more depressed and anxious than the South Korean subjects. Attention deficit is related to depression, anxiety, and PTSD. ${ }^{26-29}$ The depression and anxiety levels of our North Korean refugees were correlated with RT during the sustained attention task. However, these correlations disappeared after controlling for age and sex. Our results suggest some limited effects of depression, anxiety, or PTSD on attention among North Korean refugees.

Dissociative experience was the factor most closely related to poor attentional performance among the North Korean refugees. Dissociation is characterized by disrupted integration of various cognitive domains, including memory, perception, and self-identity. Previous studies have reported that dissociation is associated with decreased attentional ability. ${ }^{30,31}$ Early dissociative experiences have been associated with poor performance on cognitive tasks. ${ }^{32}$ The relationship between dissociation and cognition is more prominent in terms of attention and inhibition compared to strategy and planning. ${ }^{32}$ Previous studies have reported that dissociative experiences during childhood predict later attention problems in abused children. ${ }^{33,34}$ Our results suggest that dissociative experiences play a critical role in the maintenance and control of attention, particularly in individuals who are more vulnerable to traumatic or stressful situations, such as refugees.

The current results suggest that refugees' attention deficits 
may indicate the presence of psychiatric problems, particularly dissociation. In addition, dissociative experiences may herald the presence of attention problems in refugee populations. Clinicians should pay attention to dissociation and other psychiatric symptoms when they encounter refugees complaining of cognitive decline or attention deficit. Appropriately treating any of the psychiatric problems experienced by refugees may improve their attention and promote better socio-occupational adaptation.

The present study had several limitations. First, the sample size was too small to detect some of the subtle relationships between attention deficit and its correlates. Future studies with larger sample sizes may be better able to detect additional correlates of attentional deficits in refugees. Second, we could not evaluate changes in attention or psychiatric symptoms longitudinally; thus, whether the attention deficits of our North Korean refugees pre-dated or followed the dissociative experiences or onset of other psychiatric symptoms remains unclear. A longitudinal study may be needed to investigate changes in attention, nutrition, or psychiatric symptoms-including dissociative experiences-before departure from North Korea. However, such a longitudinal study design would be practically implausible in the current situation. Third, cognitive domains besides sustained and divided attention were not assessed in the current study. In addition, the previous studies using CAT were mainly on high school student. ${ }^{23-25}$ The current study shows that CAT can be applicable also to adults successfully. However, more studies may be needed for proving usefulness of CAT for adults.

In summary, North Korean refugees showed poorer performance on sustained and divided attention tasks compared to South Koreans. In addition, the poor performance on the attention tasks of our North Korean refugees was associated with their dissociative experiences. Our finding suggests that attention deficits may be common in refugees and that the attentional deficits of refugees may be caused by psychological dissociation. Our results also suggest that clinicians should evaluate and manage psychiatric symptoms, particularly dissociative symptoms, to enhance attention in refugees, and their ability to adapt cognitively to a new society.

\section{Acknowledgments}

This study was supported by grant No. 03-2013-0110 from the SNUH Research Fund and a National Research Foundation of Korea (NRF) grant funded by the Korean government (MEST) (No. 2013R1A1A2A10007021).

\section{REFERENCES}

1. Steel Z, Chey T, Silove D, Marnane C, Bryant RA, van Ommeren M. Association of torture and other potentially traumatic events with mental health outcomes among populations exposed to mass conflict and displacement: a systematic review and meta-analysis. JAMA 2009; 302:537-549.
2. Bhugra D. Migration, distress and cultural identity. Br Med Bull 2004; 69:129-141.

3. Kaplan I, Stolk Y, Valibhoy M, Tucker A, Baker J. Cognitive assessment of refugee children: effects of trauma and new language acquisition. Transcult Psychiatry 2016;53:81-109.

4. Weinstein CS, Fucetola R, Mollica R. Neuropsychological issues in the assessment of refugees and victims of mass violence. Neuropsychol Rev 2001;11:131-141.

5. Ampaabeng SK, Tan CM. The long-term cognitive consequences of early childhood malnutrition: the case of famine in Ghana. J Health Econ 2013;32:1013-1027.

6. Laude M. Assessment of nutritional status, cognitive development, and mother-child interaction in Central American refugee children. Rev Panam Salud Publica 1999;6:164-171.

7. Daud A, Rydelius PA. Comorbidity/overlapping between ADHD and PTSD in relation to IQ among children of traumatized/non-traumatized parents. J Atten Disord 2009;13:188-196.

8. Vaage AB, Garlov I, Hauff E, Thomsen PH. Psychiatric symptoms and service utilization among refugee children referred to a child psychiatry department: a retrospective comparative case note study. Transcult Psychiatry 2007;44:440-458.

9. Kivling-Boden G, Sundbom E. Cognitive abilities related to post-traumatic symptoms among refugees from the former Yugoslavia in psychiatric treatment. Nord J Psychiatry 2003;57:191-198.

10. Gomez-Perez E, Ostrosky-Solis F. Attention and memory evaluation across the life span: heterogeneous effects of age and education. J Clin Exp Neuropsychol 2006;28:477-494.

11. Jeon WT, Yu SE, Cho YA, Eom JS. Traumatic experiences and mental health of North Korean refugees in South Korea. Psychiatry Investig 2008;5:213-220.

12. Park YS, Park SM, Jun JY, Kim SJ. Psychiatry in former socialist countries: implications for North Korean psychiatry. Psychiatry Investig 2014;11:363-370.

13. Ahn JH, Kim WH, Choi HJ, Jeon JY, Song IG, Bae JN. Stigma of mental illnesses as perceived by North Korean defectors living in South Korea. Psychiatry Investig 2015;12:9-15

14. Kim HH, Lee YJ, Kim HK, Kim JE, Kim SJ, Bae SM, et al. Prevalence and correlates of psychiatric symptoms in North Korean defectors. Psychiatry Investig 2011;8:179-185.

15. Jun JY, Lee YJ, Lee SH, Yoo SY, Song J, Kim SJ. Association between defense mechanisms and psychiatric symptoms in North Korean Refugees. Compr Psychiatry 2015;56:179-87.

16. Park J, Jun JY, Lee YJ, Kim S, Lee SH, Yoo SY, Kim SJ. The association between alexithymia and posttraumatic stress symptoms following multiple exposures to traumatic events in North Korean refugees. J Psychosom Res 2015;78:77-81.

17. Lee YG, Jun JY, Lee YJ, Park J, Kim S, Lee SH, et al. Insomnia in North Korean Refugees: association with depression and post-traumatic stress symptoms. Psychiatry Investig 2016;13:67-73.

18. Hahn HM, Yum TH, Shin YW, Kim KH, Yoon, DJ, Chung KJ. A standardization study of Beck Depression Inventory in Korea. J Korean Neuropsychiatr Assoc 1986;25:487-502.

19. Yook SP, Kim ZS. A clinical study on the Korean version of Beck Anxiety Inventory: comparative study of patient and non-patient. Korean J Clin Psychol 1997;16:185-197.

20. Eun HJ, Kwon TW, Lee SM, Kim TH, Choi MR, Cho SJ. A study on reliability and validity of the Korean version of impact of event scalerevised. J Kor Neuropsychiatr Associ 2005;44:1015-1017.

21. Carlson EB, Putnam FW, Ross CA, Torem M, Coons P, Dill DL, et al. Validity of the Dissociative Experiences Scale in screening for multiple personality disorder: a multicenter study. Am J Psychiatry 1993;150: 1030-1036.

22. Yoo HK, Lee J, Kang SH et al. Standardization of the comprehensive attention test for Korean children and adolescents. J Korean Acad Child Adolesc Psychiatry 2009;20:68-75 
23. Kim SJ, Lee YJ, Cho SJ, Cho IH, Lim WY, Lim WJ. Relationship between weekend catch-up sleep and poor performance on attention tasks in korean adolescents. Arch Pediat Adol Med 2011;165:806-812.

24. Kim SJ, Lee YJ, Jang JH, Lim W, Cho IH, Cho SJ. The relationship between psychotic-like experiences and attention deficits in adolescents. J Psychiatr Res 2012;46:1354-1358.

25. Kim SJ, Kang SG, Cho IH, Lee YJ, Hong JP, Park J, et al. The relationship between poor performance on attention tasks and increased suicidal ideation in adolescents. Eur Child Adolesc Psychiatry 2015;24: 1361-1368.

26. Vilgis V, Silk TJ, Vance A. Executive function and attention in children and adolescents with depressive disorders: a systematic review. Eur Child Adolesc Psychiatry 2015;24:365-384.

27. Jarrett MA, Ollendick TH. A conceptual review of the comorbidity of attention-deficit/hyperactivity disorder and anxiety: implications for future research and practice. Clin Psychol Rev 2008;28:1266-1280.

28. Pannu Hayes J, Labar KS, Petty CM, McCarthy G, Morey RA. Alterations in the neural circuitry for emotion and attention associated with posttraumatic stress symptomatology. Psychiatry Res 2009;172:7-15.
29. Seo JY, Lee CS, Park CS, Kim BJ, Cha BS, Lee SJ, et al. Mediating effect of depressive symptoms on the relationship between adult attention deficit hyperactivity disorder and quality of life. Psychiatry Investig 2014;11: 131-136.

30. Brewin CR, Ma BY, Colson J. Effects of experimentally induced dissociation on attention and memory. Conscious Cogn 2013;22:315-323.

31. Endo T, Sugiyama T, Someya T. Attention-deficit/hyperactivity disorder and dissociative disorder among abused children. Psychiatry Clin Neurosci 2006;60:434-438.

32. Cromer LD, Stevens C, DePrince AP, Pears K. The relationship between executive attention and dissociation in children. J Trauma Dissociation 2006; 7:135-153.

33. Kaplow JB, Hall E, Koenen KC, Dodge KA, Amaya-Jackson L. Dissociation predicts later attention problems in sexually abused children. Child Abuse Negl 2008;32:261-275.

34. Matsumoto T, Imamura F. Association between childhood attentiondeficit-hyperactivity symptoms and adulthood dissociation in male inmates: preliminary report. Psychiatry Clin Neurosci 2007;61:444-446. 